\title{
The Construction of Education Cloud Environment for Interactive Teaching
}

\author{
Yi Dai \\ School of Information Technology in Education \\ China South China Normal University \\ Guangzhou, China \\ 53548708@qq.com
}

\author{
Tao Xie \\ Department of Computer Science and Technology \\ Xi'an Jiaotong University \\ Xi'an, China \\ grabertao@gmail.com
}

\author{
Fei Wan \\ Department of Adult Education \\ Zhuhai City Polytechnic \\ Zhuhai, China \\ Xiner198509@163.com
}

\begin{abstract}
Information technology, which is not only the aided teaching tool but has also become the platform supporting the new teaching mode, is changing the traditional teaching structure to the new student-centered one. Especially with the onset of the cloud era in recent years, the symbol of which is cloud computing, cloud platform and cloud learning has promoted the development of a new interactive teaching based on cloud computing. Zhuhai City became one of the first batch of smart cities and is also a first-batch pilot city of Guangdong Education Cloud project by the Education Department of Guangdong province. According to the regional pilot of Zhuhai, this paper took interactive teaching as a teaching method adapting to the environment of cloud education, built a complete set of regional cloud learning platform, and provided the situated learning, collaborative learning and ubiquitous learning services. And the paper explored how interactive teaching supported by cloud computing can help improve both teaching and learning from three aspects, i.e., environment, content security and education teaching exploration, in order to provide reference for educators.
\end{abstract}

Keywords-Interactive teaching; Learning model; Cloud computing; Educational resources; Web-based learning

\section{INTRODUCTION}

The new curriculum reform wave spawned this new exciting 'student-centered' teaching mode. It helped contemporary curriculum theory and practice to grow simultaneously, and gradually fostered different modes of interactive learning. Teaching, including the teaching and learning processes, involves two subjects called teachers and students, and the two subjects and processes are unified in teaching [1]. In order to promote students' subjective development constantly and cultivate high-quality talents, the traditional teaching mode should be replaced by the teacherstudent interactive teaching mode to make it a process that can realize the common development of teachers and students in an interaction and blend of knowledge, emotion, thought and spirit [2]. Because of this 'change' and 'fusion', interactive teaching becomes the leading concept of the new curriculum reform. As a kind of subjective teaching method, interactive teaching promotes discussion, inquiry and dialogue, achieves consensus on ideas and intelligence and constructs the sense of knowledge to accelerate the generation, publicity, development and promotion of human subjectivity constantly. In recent years, topics and papers related to research on interactive teaching have been numerous. Most of them present the teachers' perspective, rich in experience, but lacking macroscopic theoretical thinking. In order to make the study of interactive teaching more systematic, regional macroteaching implementation strategies need to be promoted vigorously to lead and guide teaching reform.

The city of Zhuhai where we worked is listed as a national pilot city in the 'Smart City' project, to be implemented within the next 3 years. Smart education is an important part of smart city construction and so a specific regional teaching implementation strategy is very urgently needed. Zhuhai is also the first experimentation area in the 'Guangdong Education Cloud' plan as part of the Guangdong education informatization twelfth five-year development plan. This paper, supported by the Zhuhai smart city project and Guangdong Education Cloud plan, discusses how to improve teaching and learning through the following three aspects: environment construction, content security and teaching exploration.

\section{RELATED WORK}

\section{A. State of the art}

As shown in Fig. 1, the $\mathrm{x}$-axis and y-axis represent the year and the number of papers published. A search of the academic trends using 'interactive teaching' as the keyword in a China National Knowledge Infrastructure (CNKI) database shows that this has been an area of great attention from 1997 to 2012, declining a little in 2013. 


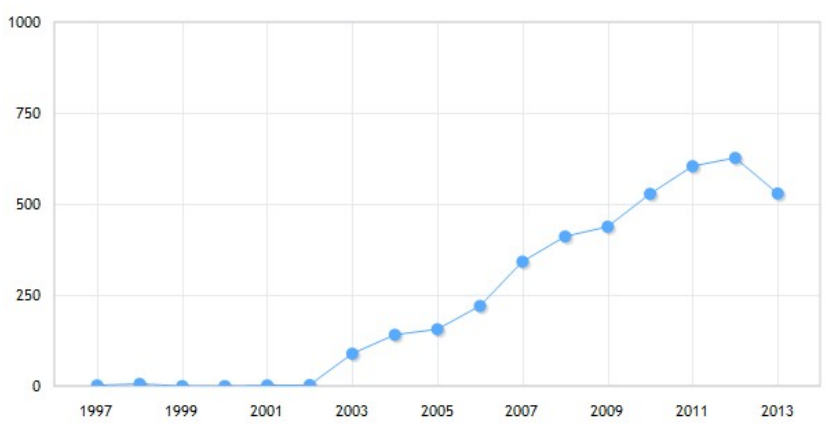

Fig. 1. CNKI ‘interactive teaching’ academic trend

The literature survey yielded a total of 3,517 articles/publications/dissertations from the year 1995 to 2013, including 1,821 articles of Chinese academic journal network publication, 1,171 feature periodicals, 177 outstanding masterlevel dissertations and 2 full-text doctoral dissertations relating to theory review, subject application, practice research, emotional attitude and evaluation measurement in interactive teaching. From the research angle, there are 1,065 articles associated with basic education and 302 associated with higher education. Master-level theses such as 'Teacher-student interactive teaching mode discussion in biology teaching of middle school' and 'Interaction in the mathematics classroom teaching strategies' summarized the interactive teaching strategy, often combined with concrete subject teaching. For example, a doctoral dissertation of Shanghai International Studies University named 'Communicative interactive implementation research on foreign language class in university' analyses interactive teaching and sums up strategies to promote it. It is therefore evident that interactive teaching has been widely carried out in primary and secondary schools and even universities with a wide range of applications, with domestic theoretical study receiving a lot of attention too.

\section{B. The cloud for interactive teaching}

Cloud computing has changed three aspects: application to interpersonal relationship, i.e. the computer to the user, isolated data to free access and shared data. It will be a collaborative computing world driven by cloud computing in the future. The application of cloud computing has received much attention and affirmation in the field of education. The profound influence of cloud computing on human learning is not just limited to introduction of new technology: new applications encourage people to rethink the learning methods and design of learning resources and environment so as to improve human learning. Cloud computing is conducive for interactive teaching in that it not only meets the needs of learners of different learning styles, such as blended learning, informal learning, lifelong learning and mobile learning, but also reduces the cost of network learning. Moreover, it makes learning support service system possible for mass storage and large-scale calculations, such as storage of high-quality network courses, fast access to play networks, high-density visits, large-scale real-time online classroom and interactive videos. With the advantage of cloud computing, a variety of resources and interactive tools are provided, studied and shared by all the participants. Thus, cloud environment provides good basic support for the development and publicity of interactive teaching. Meanwhile, interactive teaching has, to some extent, promoted and influenced the development, construction and improvement of the cloud learning environment.

\section{METHOD}

\section{A. The construction of environment}

The future informatization learning environment will be very complex with widening learning resources. Cloud computing helps solve the confusion of plateau period, such as eliminating information isolation to realize information interconnection, resource sharing and application intercommunication etc. Therefore, information education needs to step onto the cloud services platform [3]. The intelligence learning environment, along with the development of education cloud, has also attracted attention. As the advanced form of digital learning environment, the intelligence learning environment is an interactive tool which can sense the learning situation, identify learners' characteristics, provide suitable learning resources and convenient interactive tools, automatically record the learning process and evaluate learning outcomes. It is the activity space to promote effective learning and is the inevitable result of the development of education technology [4]. This paper considers the characteristics of interactive teaching and determines that the education cloud environment must adapt to a variety of learning methods, because learning under the cloud environment emphasizes free access to learning resources. With access to the Internet, learners can easily access learning resources at their convenience. The construction of education cloud environment should take into consideration the following four aspects:

- The cloud environment must be clear to the learner as the center, and give full play to his/her autonomous learning ability.

- It must promote the construction and development of integrative and open cloud learning environment.

- It must provide various learning resources and personalized support services.

- It must construct a learning environment which supports multi-terminal access and is suitable for a variety of learning methods.

\section{B. Embedding cloud}

Interactive teaching subverts the traditional 'teachercentered' concept, such that the teacher is no longer the exclusive authority of knowledge but is the students' learning partner. The students are not passive receivers of knowledge, but learning subjects, who with their interests, needs and ideas hold direct dialogue with the objective world and gain experience under the guidance of teachers. Both teachers and students explore knowledge and construct the meaning and value of life [5]. Education cloud environment, as the core part supporting the development of interactive teaching, including learning terminal, platform environment, learning tools, 
massive high-quality resources, implementation of cloud storage and management, provides the environment and communication tools for learning activities through the unified login authentication of cloud platform, integrates resources of digital teaching material, the classroom teacher and the oral test system. Cloud learning environment not only supports multi-user access, environment integration access and multiterminal access, but also informal learning, blended learning and mobile learning. All the learning, teaching and management activities of teachers and students in the interactive teaching process are completed in a cloud environment, carried out in different environments such as offices, homes and public places. It provides access to all terminals (including mobile ones), supports the breakpoint learning of the same account between different locations, teacher-teacher and teacher-student mode collaborative communication and real-time interaction, and creates an integrated, personalized and systematic learning environment for learners. According to the interactive teaching model in cloud environment, this paper designs the teaching process shown in Table 1 . The cloud learning environment's characteristics such as group cooperation and seamless connection have changed the traditional learning and teaching mode, provided a broader space for sharing of educational resources and played an important role in the development of interactive teaching.

TABLE I. DESIGN OF INTERACTIVE TEACHING PROCESS IN CLOUD LEARNING ENVIRONMENT.

\begin{tabular}{|c|c|c|c|c|c|}
\hline \multirow[b]{2}{*}{ Role } & \multirow[b]{2}{*}{ Before class } & \multicolumn{3}{|c|}{ In the class } & \multirow[b]{2}{*}{ After class } \\
\hline & & $\begin{array}{l}\text { Learning environment } \\
\text { creation }\end{array}$ & Interactive exploration & knowledge construction & \\
\hline Teacher & $\begin{array}{l}\text { Organize the teaching } \\
\text { activities; } \\
\text { Download high quality } \\
\text { resources; } \\
\text { Prepare for lessons. }\end{array}$ & $\begin{array}{l}\text { Play teaching resources; } \\
\text { Import new lesson; } \\
\text { Create a learning } \\
\text { situation. }\end{array}$ & $\begin{array}{l}\text { Send white screen; } \\
\text { Interactive inquiry. }\end{array}$ & $\begin{array}{c}\text { Coach; } \\
\text { Check the students' } \\
\text { knowledge construction }\end{array}$ & $\begin{array}{c}\text { Organize learning } \\
\text { evaluation; } \\
\text { Analyze measurement } \\
\text { results; } \\
\text { Customize review plan. }\end{array}$ \\
\hline student & $\begin{array}{l}\text { Autonomous learning } \\
\text { of interactive courses; } \\
\text { Prep evaluation; } \\
\text { A priori knowledge } \\
\text { evaluation. }\end{array}$ & $\begin{array}{l}\text { Watching the teaching } \\
\text { resources; } \\
\text { Situated learning. }\end{array}$ & $\begin{array}{c}\text { Writing on the } \\
\text { whiteboard\& creation; } \\
\text { Collaborative editing } \\
\text { creation }\end{array}$ & $\begin{array}{c}\text { Knowledge } \\
\text { construction using tools } \\
\text { like the Mind Map and } \\
\text { WPS(Education } \\
\text { Version) }\end{array}$ & $\begin{array}{l}\text { Independent practice; } \\
\text { consolidation and } \\
\text { improvement; } \\
\text { Individual review plan. }\end{array}$ \\
\hline
\end{tabular}

\section{Technical support}

We have designed three kinds of classrooms: cloud services, cloud interactive and collaborative. The cloud service class, designed for all classrooms of the city, uses the resources and platform provided to teach with devices like projectors and electronic whiteboard. The cloud interactive classroom is the wisdom classroom established in the pilot schools, which studies information-based teaching patterns and methods to effectively improve teaching quality with everyone owning a learning terminal. The cloud collaborative classroom uses the Zhuhai education video networks and cloud vision services to implement cooperative teaching among classrooms and share educational resources.

We selected a group of schools where the basic environmental construction and information-based teaching applications have had good effect as a pilot school. These schools include those located in the center of the city and a relatively remote and backward rural area. The experimental scheme is customized according to school characteristics. For example, high-quality education resources are obtained by remote collaborative learning in western backward areas, while the No.4 Middle School of Zhuhai, located in the South of China, tries to make breakthroughs in the education reform by subverting the traditional teaching mode and learning through the micro-course platform and flipped classroom.

We provided Mind-Cloud classroom for carrying out cloud integrated teaching in these experimental schools whenever and wherever possible. In the learning environment of one terminal in everyone's hand, we could research on the information teaching pattern and methods to improve teaching quality, explore the application scene and mode of subject teaching tools and try to put forward the method and mode of new teaching environment comprising digital textbooks, subject teaching tools and cloud services.

In addition, with regard to the professional development of teachers, we built a 'research-training application' integrated platform, organized network space for everyone, carried out network collaborative research across the region and developed teacher training courses. Our purpose is to realize co-construction and sharing by introducing and developing famous teachers' classrooms, special digital education resources and school-based network curriculum.

\section{ApPliCATION In Digital TeXTBOOKS}

Primary and middle school textbooks are the basis for the teacher to implement class teaching, and a major source of students' knowledge. Digital learning content, as the cloud core elements of learning environment, plays an important role in teaching reform. The core of digital learning content is the digital textbook, which is three-dimensional, interactive and intelligent. Taking the original paper textbooks as the interface, the digital textbook expands the contents of textbooks, provides functions of teaching design, evaluation and management and permeates every process of teaching. The digital textbook can integrate conveniently with the cloud platform according to teaching and learning needs.

Therefore, the city of Zhuhai imports the digital textbook into the classroom and carries out the experiment of its normalization in teaching application based on the Guangdong Education Cloud digital education resources in order to research the application mode of digital textbooks for primary 
and middle school classrooms. This experiment in Zhuhai is the best example of the full realization of classes in education informatization. The digital textbooks not only promote the resource share, but also improve the efficiency in the use of existing education informatization equipment. In addition, educational video nets have also been built in Zhuhai, connecting with the Guangdong Education Cloud and the Guangdong education video network so that the high-quality education resources can reach rural and weak schools, which is good for the balanced development of education resources in urban and rural areas.

\section{CONCLUSION}

The 'Smart City' construction of Zhuhai is in urgent need of innovations in teaching modes. In order to make breakthroughs more systematically and deeply in the study of interactive teaching, regional macro-teaching implementation strategy is explored in this paper. The city of Zhuhai is listed as the first experimentation area of the Guangdong Education Cloud project. This paper takes Zhuhai as a regional pilot, builds a complete regional cloud learning platform and discusses how to improve teaching and learning in the environment of cloud computing from the following three aspects: environment construction, content security and teaching exploration. We hope this will serve as a reference for educators.

\section{ACKNOWLEDGMENT}

This research was financially supported by the national education information technology research project in 2016 (No.163623379) and the Guangdong Province Education Research '12th Five-Year' planning research project in 2015(No.15JXN009).

\section{REFERENCES}

[1] Xie, S.A., Exploration and thinking about the design of interactive teaching in university, Education Exploration, (1), pp. 61-63, 2010.

[2] Huang, F.Q., Curriculum reform in contemporary China: seven goals and six strategies. Journal of Curriculum Studies, Vol. 36, Iss. 1, pp. 101-115, 2004.

[3] Aljenaa, E, Al-Anzi, F.S., Alshayeji, M. To-wards an efficient e-learning system based on Cloud computing. Proceedings of the Second Kuwait Conference on e-Services and e-Systems (KCESS'11), USA: New York. April 6, 2011.

[4] Huang, R.H., Yang, J.F. \& Hu, Y.B., From the digital learning environment to the intelligence learning environment - changes and trends of learning environment. Open Education Research, vol. 1, pp. 75-84, 2012.

[5] Sun, Z.W., on the connotation, characteristic and implementation principle of interactive teaching. Education Exploration, vol. 11, pp. 1214, 2008 